\title{
Neonatal lupus presenting as a butterfly rash
}

\author{
Jerome Coulombe MD, Julie Barsalou MD MSc
}

- Cite as: CMAJ 2021 May 31;193:E805. doi: 10.1503/cmaj.202246

A 3-month-old African American boy was referred to the dermatology clinic with a 2-month history of skin hypopigmentation that his pediatrician had diagnosed as vitiligo. Before hypopigmentation developed, the rashes were erythematous. The boy was born at term via normal vaginal delivery after an uneventful pregnancy, and was tracking in the 90th centile for expected head circumference and weight development. He had 2 healthy siblings, and there was no family history of autoimmune disease.

The hypopigmentation involved a striking butterfly-shaped facial rash (Figure 1) and multiple oval patches on the patient's abdomen (Appendix 1, available at www.cmaj.ca/lookup/ doi/10.1503/cmaj.202246/tab-related-content). There were no signs of atopic or seborrheic dermatitis. Because of the distinctive rash, we suspected neonatal lupus erythematosus and investigated accordingly. Both the infant and his mother tested positive for antinuclear and anti-Ro antibodies. The baby's electrocardiogram, echocardiogram, complete blood count and liver enzymes were normal. We diagnosed cutaneous neonatal lupus erythematosus, advised photoprotection and prescribed a 3-month course of tacrolimus $0.03 \%$ ointment, applied twice daily. At 12 months, the patient's skin lesions had resolved and autoantibodies were negative. The mother did not show signs of an autoimmune disease, but future pregnancies will be monitored closely.

Neonatal lupus erythematosus is an uncommon condition resulting from the passive transfer of maternal anti-Ro, anti-La or anti-ribonucleoprotein antibodies from mother to baby. ${ }^{1}$ It is characterized by the development of typical dermatological signs, congenital heart block and endocardial fibroelastosis. Infants with the condition can also present with hepatobiliary disease, cytopenias, macrocephaly or hydrocephalus. ${ }^{2}$ Vitiligolike presentations of neonatal lupus erythematosus have been

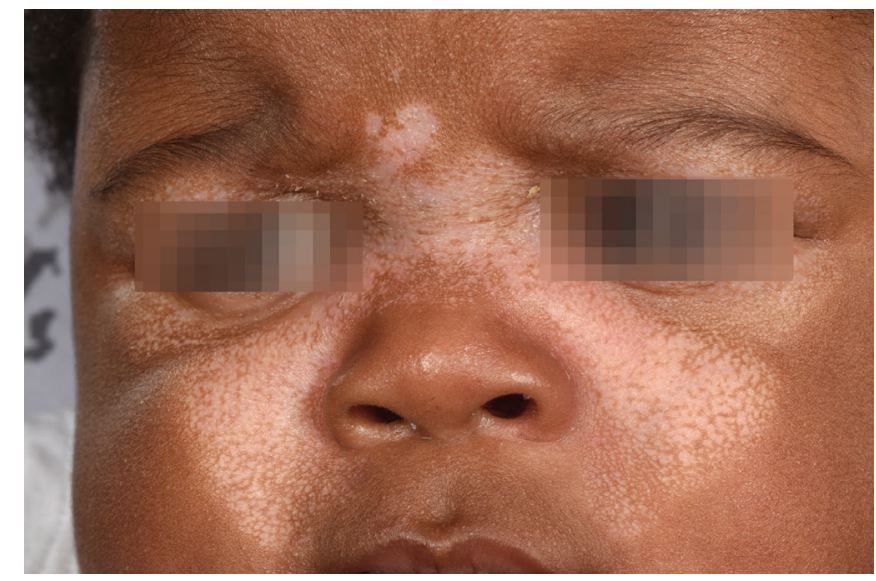

Figure 1: Striking butterfly-shaped hypopigmentation on the face of a 3-month-old boy with neonatal lupus erythematosus.

described in infants with darker skin. ${ }^{3}$ Vitiligo presenting in the neonatal period is exceptional and should prompt clinicians to investigate further. Subsequent pregnancies in women who have given birth to a child with either cardiac or cutaneous neonatal lupus erythematosus warrant maternal and fetal cardiac monitoring, as the risk of having a child with cardiac neonatal lupus erythematosus increases to $20 \% .{ }^{1}$

\section{References}

1. Vanoni F, Lava SAG, Fossali EF, et al. Neonatal lupus erythematosus syndrome: a comprehensive review. Clin Rev Allergy Immunol 2017;53:469-76.

2. Boros CA, Spence D, Blaser S, et al. Hydrocephalus and macrocephaly: new manifestations of neonatal lupus erythematosus. Arthritis Rheum 2007;57: 261-6.

3. Jenkins RE, Kurwa AR, Atherton DJ, et al. Neonatal lupus erythematosus. Clin Exp Dermatol 1994;19:409-11.
Competing interests: Jerome Coulombe reports receiving personal fees from Galderma, Leo Pharma, Novartis and Pfizer, outside the submitted work. No other competing interests were declared.

This article has been peer reviewed.

The authors have obtained consent from the patient's parents.

Affiliations: Dermatology (Coulombe) and Rheumatology (Barsalou), Department of Pediatrics, CHU Ste-Justine, Université de Montréal, Montréal, Que.
Content licence: This is an Open Access article distributed in accordance with the terms of the Creative Commons Attribution (CC BY-NC-ND 4.0) licence, which permits use, distribution and reproduction in any medium, provided that the original publication is properly cited, the use is noncommercial (i.e., research or educational use), and no modifications or adaptations are made. See: https://creativecommons.org/licenses/ by-nc-nd/4.0/

Correspondence to: Jerome Coulombe,

jerome.coulombe@umontreal.ca 